\title{
The Virtual Clinic: Two-sided Affordances in Consultation Practice
}

\author{
Anna Sigridur Islind ${ }^{1,2} *$ (D), Ulrika Lundh $\mathrm{Snis}^{2}$, Tomas Lindroth ${ }^{2}$, Johan Lundin ${ }^{3}$, \\ Katerina Cerna ${ }^{4} \&$ Gunnar Steineck ${ }^{5}$ \\ ${ }^{* 1}$ School of Computer Science, Reykjavik University, Reykjavik, Iceland (E-mail: annasi@ru.is); \\ ${ }^{2}$ School of Business, Economics \& IT, University West, Trollhattan, Sweden (E-mail: annasi@ru.is); \\ ${ }^{3}$ Department of Applied IT, University of Gothenburg, Gothenburg, Sweden; ${ }^{4}$ Department of \\ Education, Communication and Learning, University of Gothenburg, Gothenburg, Sweden; \\ ${ }^{5}$ Department of Oncology, University of Gothenburg, Gothenburg , Sweden
}

\begin{abstract}
Telecare has the potential to increase the quality of care while also decreasing costs. However, despite great potential, efficiency in care practices and cost reduction remain hypothetical. Within computer supported cooperative work (CSCW), one focus of telecare research has been on awareness support in distributed real-time communication in comparison to physical meetings since face-to-face consultations have been known as the "gold standard" of conducting care. Research has shown that it is hard to maintain qualities such as awareness through video-mediated meetings. In this research, the goal has not been to mimic the qualities of face-to-face consultations but rather to document the qualities of three types of patient meetings (consultations) and to understand in what kinds of situations each consultation type is a viable option. In this paper, we focus on the essential qualities of i) face-to-face consultations, ii) video-based consultations, and iii) telephone consultations and shed light on their affordances. The research contribution includes an extension of the affordance lens to incorporate socio-technical, two-sided affordances, that constitute important aspects for understanding complexity when heterogeneous actors co-existing in a practice, where affordances can differ for different "sides" in the complex practice- a view that is fruitful when dealing with heterogeneous actors and a set of analog and digital tools in a practice.
\end{abstract}

Key words: telecare, telehealth, virtual clinic, affordances, practice, qualities, two-sided affordances, multi-sided affordances, consultations

\section{Introduction}

Telecare has the potential to increase patient empowerment and the quality of care while also decreasing costs and promoting improved access (Andersen et al. 2018; Holman and Lorig 2004; Johnston et al. 2013; Koch 2006; Street Jr et al. 2005). Despite great potential, efficiency in care practices and cost reduction remain hypothetical, leaving many of the promises yet to be fulfilled (Andersen et al. 2018; Archer et al. 2011; Dedding et al. 2011).

During a regular face-to-face meeting, there is a factor of awareness about the others' tasks and reactions. Awareness contributes to richness and is the key to 
coordinating actions in the face-to-face meeting. Awareness creates opportunities for shifting between loosely coupled activities and tightly coupled ones, which contributes to a mutual understanding of the situation (Greenberg and Gutwin 2016). However, awareness is a fuzzy concept that is hard to design into to IT artifacts meant to mimic face-to-face meetings (Greenberg and Gutwin 2016). The research within computer supported cooperative work (CSCW) has shown an interest in, and argued for, awareness support in distributed real-time communication (cf. Dourish and Bellotti 1992). The research on awareness and the design of IT artifacts that are to function as well as face-to-face meetings often takes on either groupware as a way of conducting collaborations (cf. Greenberg and Gutwin 2016; Gutwin and Greenberg 2002; Tenenberg et al. 2016) or telecare as a context for mimicking in-hospital care. What has been shown is that it is hard to maintain qualities such as awareness through video-mediation meetings (cf. Greenberg and Gutwin 2016; Tenenberg et al. 2016). In this paper, we report on a study where the goal has been neither to mimic the qualities of a face-to-face meeting nor to replace the face-to-face meeting. What we instead aim to do is document the qualities of three ways of conducting a patient meeting (hereinafter "consultation") and the kinds of situations where the different consultation types are a viable option. Face-to-face consultations have been known as the "gold standard" of conducting care and performing clinical work by a variety of researchers both within medicine and nursing as well as by clinical practitioners. That assumption is partly based on the abovementioned awareness factor. However, what happens when it is physically impossible to conduct care through face-to-face consultations and what qualities care at a distance requires and offers remain underdeveloped in previous research. In this paper, we therefore explore which qualities are essential when conducting i) face-to-face consultations, ii) videobased consultations, and iii) telephone consultations. Qualities such as awareness (alongside others) can be seen as affordances, which is the theoretical framing for this paper. Also, a practice lens is applied in order to design a new and complementary way of working out consultations.

The aim of this paper is therefore to use the logics of practice theory and affordance theory to understand how affordances emerge from the relation between the sociotechnical arrangement of heterogeneous actors and tools used to conduct the consultation practice. The consultation practice is a collaborative effort between nurses and patients. The effectiveness, quality of care and the type of delivery (i.e., face-to-face, video-based, or through telephone) are reliant upon the nurses' and patients' coordination between social and technical (in a socio-technical view) resources, which is what we wish to shed light on in this paper. The research question is: How can affordances be conceptualized to include heterogeneous actors and their sociotechnical resources in a collaborative work practice? The methodological approach is a case study where the empirical data are based on three years of project work, including observations, semi-structured interviews, workshops, and field notes.

The context of the study is a cancer rehabilitation clinic in Sweden where patients dealing with complex problems due to their cancer treatment seek care from 
specialized nurses. The goal is not to compare the consultation types but rather to analyze the interaction between the nurses and the patients during each consultation type and offer a set of qualities in terms of affordances for each type and to offer an understanding of the kinds of situations in which each consultation type is fruitful. Practically, this contributes with a step toward going from the hypothetical empowerment of patients and hopes of increased quality of care to documenting the ways in which the different consultation types can benefit or hinder the patients and the nurses. Hence, our practical contribution offers an understanding of how the enhancements of a consultation practice are being realized by providing new ways of conducting consultations (where video-based consultation is the newest addition).

We argue that the affordances differ between the actors (the nurses and the patients), and thereby we want to propose an extension of the affordance lens to include what we call two-sided or multi-sided affordances, which is based on a sociotechnical view that combines the practice lens and affordance lens and encompasses heterogeneous actors in a practice. Our argument is that two-sided or multi-sided affordances can provide further knowledge by addressing multiple connections among heterogeneous actors with different needs in complex practices, which also include a variety of tools, which can both be analog and digital. Such a multiplepurpose perspective on affordances is inspired by platform research and the twosided and multi-sided markets perspective. Similar to viewing platforms as two-sided or multi-sided markets, we argue for viewing affordances likewise. A growing body of literature concerns research regarding mobile and software-based platforms, where the main focus is on platforms as two-sided or multi-sided markets (Eaton et al. 2015; Ghazawneh and Henfridsson 2013; Islind 2018; Islind et al. 2016; Sørensen et al. 2015; Tiwana et al. 2010; Wareham et al. 2014). In that stream of research, the platform (technology) facilitates exchange between consumers that have not been in transactions before and enables interaction as the interaction takes place by way of the platform (Gawer 2014). The lens has been growing since the early 2000s and has been referred to as two-sided markets, multi-sided markets, and two-sided and multi-sided platforms in the literature (Evans 2003; Gawer 2014; Rochet and Tirole 2003, 2006; Islind 2018). Inspired by the notion of two-sidedness and multi-sidedness, we wish to shed light on two-sided and multi-sided affordances in the discussion section and contribute with that extension. We do, however, wish to explain on beforehand that we seek inspiration from multi-sidedness but do not apply the whole lens; the two-sided and multi-sided markets from the platform literature is thereby neither a part of the related work nor the theoretical framing but is rather included herein to show from where we sought the inspiration for multi-sided affordances. In this paper, we do however only consider dyad as we draw from a case of two-sided affordances but the theoretical contribution does however extend to other settings with multiple sides; multi-sided affordances.

Consequently, our view on affordances connects multiple users with various needs but still keeps together the main goal of a common practice (e.g., consultation practice) within a chain of interrelated interactions of affordances. That is to say that 
technology is no longer one single tool offered to its users but instead consists of a multiple sample of tools and services in practice - in other words, a collection of actors related to a common goal. Further elaborations on this will be provided alongside the analysis of the results and discussion.

\section{Related work}

People who are diagnosed with cancer, or other similar diseases of the same severity, are more likely than previously to survive. Cancer treatments are proving much more successful nowadays, which has both increased the chances of beating cancer as well as changed the nature of the after-care (Warrington et al. 2015). In Europe there are approximately 20 million cancer survivors, and in Sweden the number is about 390,000. In the United Kingdom alone, the number of people who have survived cancer is two million today, and this number is estimated to increase to four million by 2030 (Maddams et al. 2009; Warrington et al. 2015). This increase is considerable and is great news but also presents new challenges to healthcare and brings a new group of the chronically ill into the healthcare system. A well-known and widely debated aspect in relation to the future of healthcare is the nature of the care for the chronically ill and the increased progressiveness in cancer treatments and problems that occur after successful cancer treatments, which have not been a large part of healthcare before but are becoming pressing issues. The demand on care is predicted to increase substantially as a result of higher life expectancy due to demographic and epidemiological advancements (Harari 2016; Kalache et al. 2002; Pin and Spini 2016), and this increased demand is especially relevant when it comes to caring for the chronically ill. The care for the chronically ill is an expensive and timeconsuming aspect of healthcare, and it is a part of healthcare that is often performed by hospitalization, which is a highly costly effort. Distributing parts of that care is thereby a feasible option for several reasons. Distributing parts of care with help via information and communications technology (ICT), information systems, and digital services integrated into healthcare is often seen as an enabler of the abovementioned potentials of telecare (with decreased costs, increased patient empowerment, increased quality of care, and increased access), and information systems, incorporated into care practices, are thought to be the key solution when it comes to distributing care.

In regard to the research on digitalization within healthcare settings, the electronic patient record (EPR) is an important historical aspect, and the care sector in general has invested heavily in information systems, such as the EPR, as a support for healthcare practices (Chiasson et al., 2007; LeRouge et al., 2007; Fitzpatrick and Ellingsen 2013). The information systems efforts in healthcare have some been largescale, national standards and strategic infrastructural changes with the aim of integrating various types of healthcare systems, where the EPR has been the leading challenge since the early 2000s (Fitzpatrick and Ellingsen 2013). The focus of research is, however, shifting from the EPR as a working tool toward other 
information systems that can assist in different aspects of healthcare and not only support healthcare professionals but have the dual aim of supporting healthcare and the patients. This shift and the growing interest in the complexity of the collaboration between the heterogeneous actors is what we contribute to.

Previous work on telecare shows that technology has slowly become an integrated part of care and that technology has bearing on the meaning of care and has influence on the role of the caregiver (Islind and Lundh Snis 2017, 2018; Milligan et al. 2011; Pols and Willems 2011; Pols 2010; Procter et al. 2016; Roberts et al. 2012). Most of the work on telecare has focused on telecare performed as a part of call centers, and the care is viewed primarily in terms of distributed care in that sense (Pols 2010; Pols and Willems 2011; Milligan et al. 2011; Roberts et al. 2012; Procter et al. 2016). Many studies on telecare are, according to Kahn (2015), before-and-after studies that rarely shed light on patient-centered outcomes. Kahn (2015) calls for more research related to exploring crucial issues of contexts rather than focusing on whether or not telecare works. Kahn (2015) calls for more research regarding how, when, where, and for whom telecare works and for an overview of what types of qualities telecare can provide and also in-depth studies of aspects related to the profession as well as the patient.

In line with that call, we want to focus on telecare as a way of shifting between different ways of conducting care, where telecare is one aspect (with telephone and video-based consultations) and face-to-face consultations (not related to telecare) are another aspect. In this case, the care at the clinic is always the starting point for each patient, meaning that in this paper, telecare is an extended, augmented part of the clinic and not the primary means of contact between the caregiver and the patient. Our interest focuses on understanding consultations and not to analyze them as isolated units but rather as complementary parts of conducting the practice of consultation.

\section{Theoretical framing}

Gibson's (1977) original definition of the concept of affordances sheds light on the intrinsic, naturalistic relation between the world and animals' agency through conceptualizing the animals' perceptions and actions that are possible in relation to the environment.

"The affordances of the environment are what it offers the animal, what it provides or furnishes, either for good or ill. The verb to afford is found in the dictionary, the noun affordance is not. I have made it up. I mean by it something that refers to both the environment and the animal in a way that no existing term does. It implies the complementarity of the animal and the environment."

— Gibson (1977, p. 127) 
The concept of affordances, has, thereby, from the beginning, had to do with the relation between an organism and an object (Torenvliet 2003). Affordances are, in this sense, the action capabilities of the organism, and Gibson (1977) states that affordances exist independent from the organism but that they are, however, always in relation to the actions of the organism.

Affordances were thus first introduced by Gibson (1977) and were brought into the computer context by Norman (1988). The lens has been extended and discussed by various researchers, in which important work includes technology affordances (cf. Gaver 1991; Kaptelinin and Nardi 2012) and social affordances (Bradner 2001; Bradner et al. 1999), and more recent work sheds light on collaborative affordances (Bardram and Houben 2018). In regard to technology affordances, Gaver (1991) makes a distinction between four affordance combinations: i) perceivable affordances, ii) false affordances, iii) hidden affordances, and iv) correct rejection. Affordances can be present or absent and can exist in complex actions, which points to the notion of affordances being nested, or being connected to a sequence (Gaver 1991). Since then, the CSCW literature has applied affordances to various discussions regarding interactions and design, which has contributed to a growing understanding of the notion of affordances within CSCW (such as social affordances and collaborative affordances). The Human Computer Interaction (HCI) (where Norman entered his work) and Information Systems (IS) have also adapted the affordances lens and extended the notion of affordances, whereas the scope of this paper is rather from the $\mathrm{CSCW}$ viewpoint.

The lens of affordances has been applied to medical work and telecare (cf. Bardram and Bossen 2005; Bardram and Houben 2018; Chen 2010; Tang and Carpendale 2008). Affordances such as of flexibility, markability, portability, and accessibility alongside other applicable affordances can be found in the literature. However, there is a gap regarding the understanding of affordances in a practice that is mediated in different ways, where not all aspects are technology-mediated, where the degree of virtualization varies, and where the actors involved in the practice are heterogeneous. By virtualization we mean that some aspects of the consultation are analog, and some instances are mediated through different types of technology, where some are mediated through video and in other instances mediated through telephone.

We argue in line with others that affordances are relational and emerge through interaction between the actors and their surrounding artifacts (Van Osch and Mendelson 2011) and exist relative to the action capabilities of a particular actor (McGrenere and Ho 2000). However, affordances are neither the properties of the environment nor the characteristics of the individuals (Stoffregen 2003) but are rather relative to the characteristics of the local arrangements in its near environment- that is, the practice situated and actualized in the embedded interaction with the technology tools (e.g., features, routines, resources, knowledge, abilities, social needs, and personal intentions). Hence, there is a practice-oriented dimension of affordances as a way to explore how work practice arrangements adapt to the use of IT. For instance, 
Leonardi (2011) and Zammuto et al. (2007) used the affordances lens to capture the interplay between ICT and the organization. Leonardi (2011) specifically argues that the actualization of affordances may also result in functional constraints. Therefore, the impact of the actualization is not a one-stop phenomenon but a continuous process of the appropriation of several material (technical) properties and organizational/human (social) routines to meet the desired outcome.

Affordance is an important concept to understand the relationship between computer support and collaborative work. In the literature, affordances are more often conceptualized as a one-to-one relationship between the artifact and its user (cf. Leonardi et al. 2012). Others have found a multi-dynamic relationship between the artifact and its user, and they include the social and cultural contexts within which an artifact is situated (Orlikowski 2007). We agree that the notion of affordance needs to be seen as a dynamic, always-emerging relationship between people and their environment. In this paper, we suggest that affordances be seen in types of sociotechnical relationships that go bi-directionally, not just one way, and we thereby see the value of understanding both technology affordances as well as social affordances, together. Typically, affordances direct the opportunities that can be distinguished in resources of different kinds e.g. computer support services, in the eyes of particular objects/subjects (people). However, a bi-directional relationship herein considers not only that computer support provides its affordances to the people working in a collaborative setting but that such a situated working environment also provides the knowledge and services needed to afford that computer support (e.g., conditions such as characteristics of work, individual competence, and organizational maturity) (Cabitza and Simone 2012).

We argue that the actualization of affordances is genuinely related to the practice situated and embedded in the use of the actual technology/tools and might in turn lead to the identification of new affordances directed toward enhanced capabilities. This understanding is in line with the understanding of collaborative affordances, which is defined as "a relation between a [physical and/or digital] artifact and a set of human actors, that affords the opportunity for these actors to perform a collaborative action within a specific social context" (Bardram and Houben 2018, p. 8). However, we want to extend that notion of collaborative affordances, dig deeper into the practice lens, and shed light on the bi-directional relationship discussed above and look toward specific affordances of different ways of mediating a practice wherein the actors are heterogeneous, with different tools and levels of virtualization and distribution.

To more deeply understand the socio-technical aspect discussed above, we want to dive with more depth into the notion of practice and incorporate the practice lens as a complementary lens for this paper. Merging the affordance notion with the practice perspective is herein also done due to practice-related shortcomings in the affordances' lens. Let us elaborate. As a way to understand the social system, the practice lens has been widely applied within IS and CSCW research. The lens has been used by various researchers in different forms. There has been a focus on 
different aspects of what emerges from the practice of everyday work (Leonardi 2015). For example, Wenger (1999) focuses on how social skills emerge out of the practice of work, Orlikowski (2000) focuses on how people develop shared technology patterns, Barley and Kunda (2001) focus on how networks emerge from the practice of work, Brown and Duguid (2001) focus on how knowledge emerges, Carlile (2004) on coordination, and Nicolini et al. (2012) on people's ability to collaborate.

This research is also grounded in different theoretical standpoints. Orlikowski (2000) applied Giddens's structuration theory, Levina and Vaast (2005) applied Bourdieu's theory of practice, and Klein and Hirschheim (2008) applied Lave and Wenger's lens to understand practice. Carlile $(2002,2004)$ conceptualized division in practice and the creation of knowledge boundaries among different collaborating expert groups. However, in one form or another, the stream of literature is oriented toward the consensus of a practice being an ongoing production that emerges through everyday actions at work (Knorr-Cetina 2001; Leonardi 2015; Nicolini et al. 2012; Pickering 2001).

The understanding of what constitutes a practice is one core foundation for this research, but as we see it, affordances theory and the understanding of affordances can be enriched by a deepened understanding of a practice to grasp the sociotechnical view. For instance, a practice affords different things, not always in relation to technology. What we mean by this is that a practice, for instance consultation as a constellation of coordinated actions, can afford different things, and we thereby want to understand the technology in relation to that practice and the affordances of that technology as well as the practice in relation to the tools used. We agree that actions are grounded in objects and in space and that they are situated and unique but dependent on the context of the actions (Scollon 2002). Material objects, used to mediate actions, generate and transfer meaning while using those in specific actions (Kress 2009). A material object, or tool, either paper-based or a digital tool, can serve as a device for transformation, translation, and negotiation at the boundaries (Bartel and Garud 2003; Bechky 2003; Boland and Tenkasi 1995; Carlile 2002, 2004; Levina and Vaast 2005; Nicolini et al. 2012; Pawlowski and Robey 2004; Star and Griesemer 1989). The notion of tools as mediators of practice is thereby important.

However, a practice can be mediated by different tools, or a set of tools, which increases the complexity. Assuming a practice is an ongoing production that emerges through everyday actions at work allows for the possibility of recognizing many practices within one setting. In this sense, the consultation can be seen as a practice from which we look toward different ways of conducting and mediating that practice. Practices are complex, and a practice is not an isolated instance; instead, one practice is often intertwined with other practices (Nicolini 2012), and as practices emerge, it is interesting to see what happens when the practice is mediated in different ways, shedding light on the affordances that involve the heterogeneous actors in the practice. When practices involve heterogeneous actors (such as a patient and a nurse in the practice of consultation), and these actors use different tools but mediate their 
communication in one particular way, then the affordances can differ as well. In line with that understanding, we want to understand complex practices, such as consultations, which involve heterogeneous actors with different needs in regard to the practice. We also want to shed light herein on the various types of technology, both analogue and digital, and apply Gibson's notion of affordances due to the fact that some parts of the practice (e.g., consultation) are analogue but still consist of tools.

\section{Research approach}

This paper is based on a study of conducting consultations as a part of clinical work. The methodological approach is a case study, which includes complementary forms of data collection, as suggested by Yin (2017). Stake (1995) states that the choice of conducting a case study depends on the object to be studied rather than merely a choice of techniques or methods. Therefore, it is more relevant to discuss the case study as an approach to studying a specific phenomenon that is part of a real-life context (Benbasat et al. 1987; Hancock and Algozzine 2016; Yin 2013, 2017). It is an approach to studying the particular, often with a special focus on what is unique in a specific case in which multiple sources of evidence are used (Walsham 1995). The unique aspect of this case study is the consultations and to investigate the degree of virtualization in the consultations as a way of conducting care.

This case study is based on a three-year engagement with the aim of digitalizing parts of the clinical work at a cancer rehabilitation clinic at [hospital name blinded for review process] in Sweden. The project started in 2015 and is currently ongoing. The background data for this paper are based on 20 non-participant observation days at the clinic, which were documented in observation notes. In addition, the data consist of recordings, transcriptions, observations, and observation notes from five face-toface consultations between a nurse and a patient at the clinic. Moreover, the data also include recordings, transcriptions, observations, and observation notes from five video-mediated consultations between a nurse and a patient as well as 20 followup telephone consultations between patients and nurses. The telephone consultations tend to be shorter, strengthening the argument for including a larger selection of telephone consultations. The data are also based on semi-structured interviews with the patients individually directly after the consultations as well as interviews with the nurses afterwards (see Table 1). Additionally, the data were derived from a workshop and interviews as well as follow-up interviews with nurses conducted eight months after the video-mediated consultation was introduced as a complementary way of conducting consultations. In these interviews the more general view on the digitalized aspects of the clinic was discussed, one such aspect being the video-mediated consultation and the different consultation types. The analysis of the data was conducted in nVivo software, where transcripts of interviews and workshops alongside observation notes, ethnographic notes, and transcriptions from consultations were then coded (in line with Graneheim and Lundman 2004). The analysis has been targeted toward understanding the consultations. Table 1 below provides an 
Table 1. The empirical data for this paper.

\begin{tabular}{llll}
\hline $\begin{array}{l}\text { Number of } \\
\text { activities }\end{array}$ & $\begin{array}{l}\text { Data gathering } \\
\text { method }\end{array}$ & Actors & Duration \\
\hline 20 & Observations & Nurses and their daily work & Full work days \\
5 & Observations & Face-to-face consultations: patient + nurse & 60 min each \\
5 & Observations & Video-based consultations: patient + nurse & 50 min average \\
20 & Observations & Telephone consultations: patient + nurse & 15 min average \\
6 & Interviews & Nurse (interviews and follow-up interviews) & 60 min each \\
1 & Workshop & 3 patients +2 nurses & 120 min total \\
5 & Interviews & Patients (after consultations) & 20 min average \\
\hline
\end{tabular}

overview of the empirical data. During observations of the face-to-face consultation the observer (the first author of this paper) was in the room, observing the interaction between the nurse and the patient (see Figure 1).

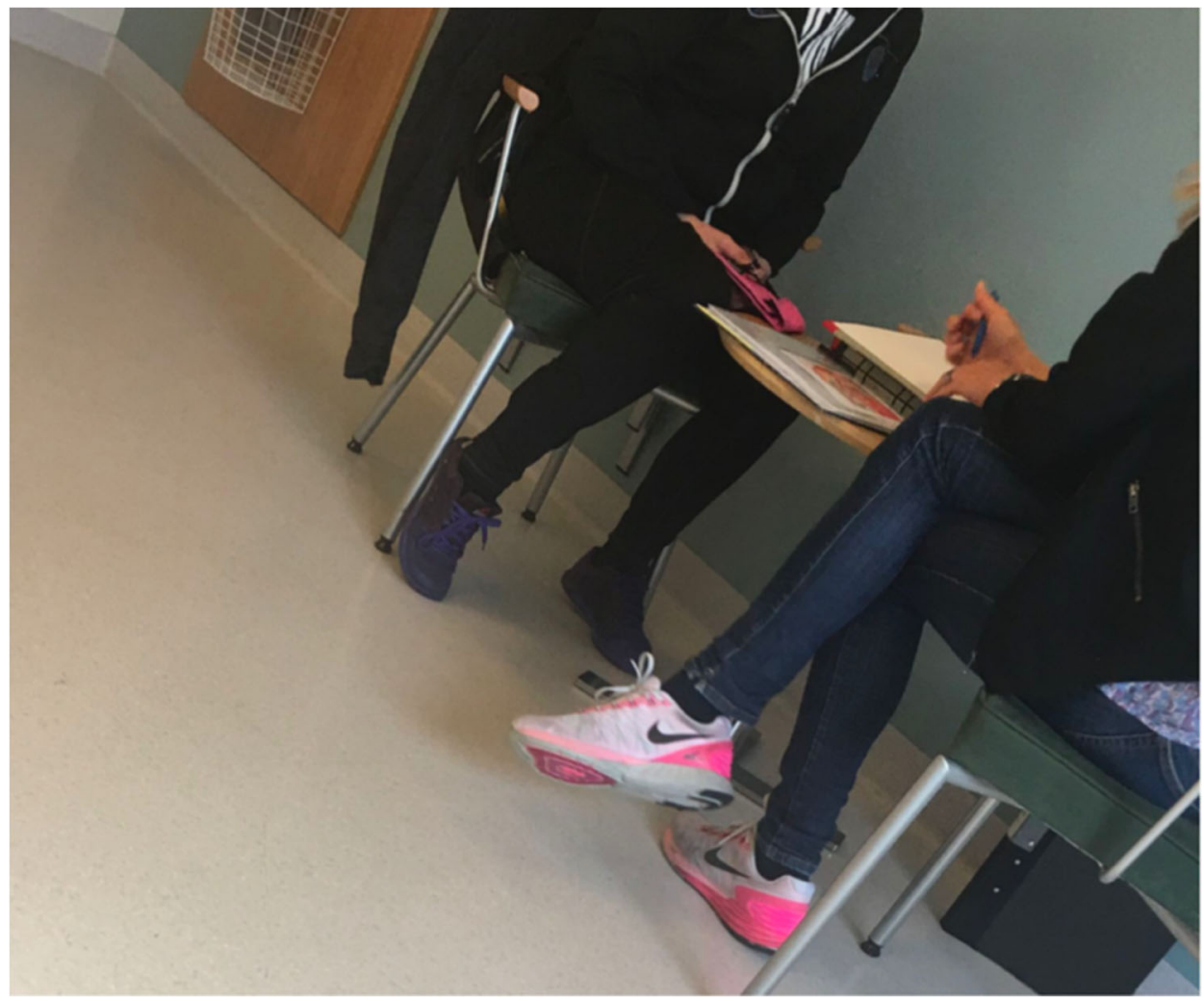

Figure 1. The view of the observer during face-to-face consultations, the picture has been cut for anonymity but is taken from the seat where the observer was sitting. The person in pink shoes is a nurse and the other person is a patient, showing her data on her mobile phone. 
During the video-based consultations, the observer (again, the first author of this paper) was in the room with the nurse. The location of the observer was behind the nurse and to the left during observations. Figure 1 is included to show what the observer saw during observations. The observer was able to see the patient file (on the larger screen in Figure 2), the video-mediated consultation (on the smaller screen in Figure 2) and see everything that the patient did and showed during observations. The nurse and the patient were able to share text via the messages that can also be seen on the smaller screen in Figure 2. The nurses' preparation notes can be seen in the folder and the calendar is next to the nurse, so that she can easily find a new appointment for the next consultation. In front of the nurse is her notepad, where she keeps the notations for medication that need to be prescribed by the physician.

During the interviews after the video-mediated consultations the nurse went out of the room and the observer moved to the place where the nurse is standing and did the

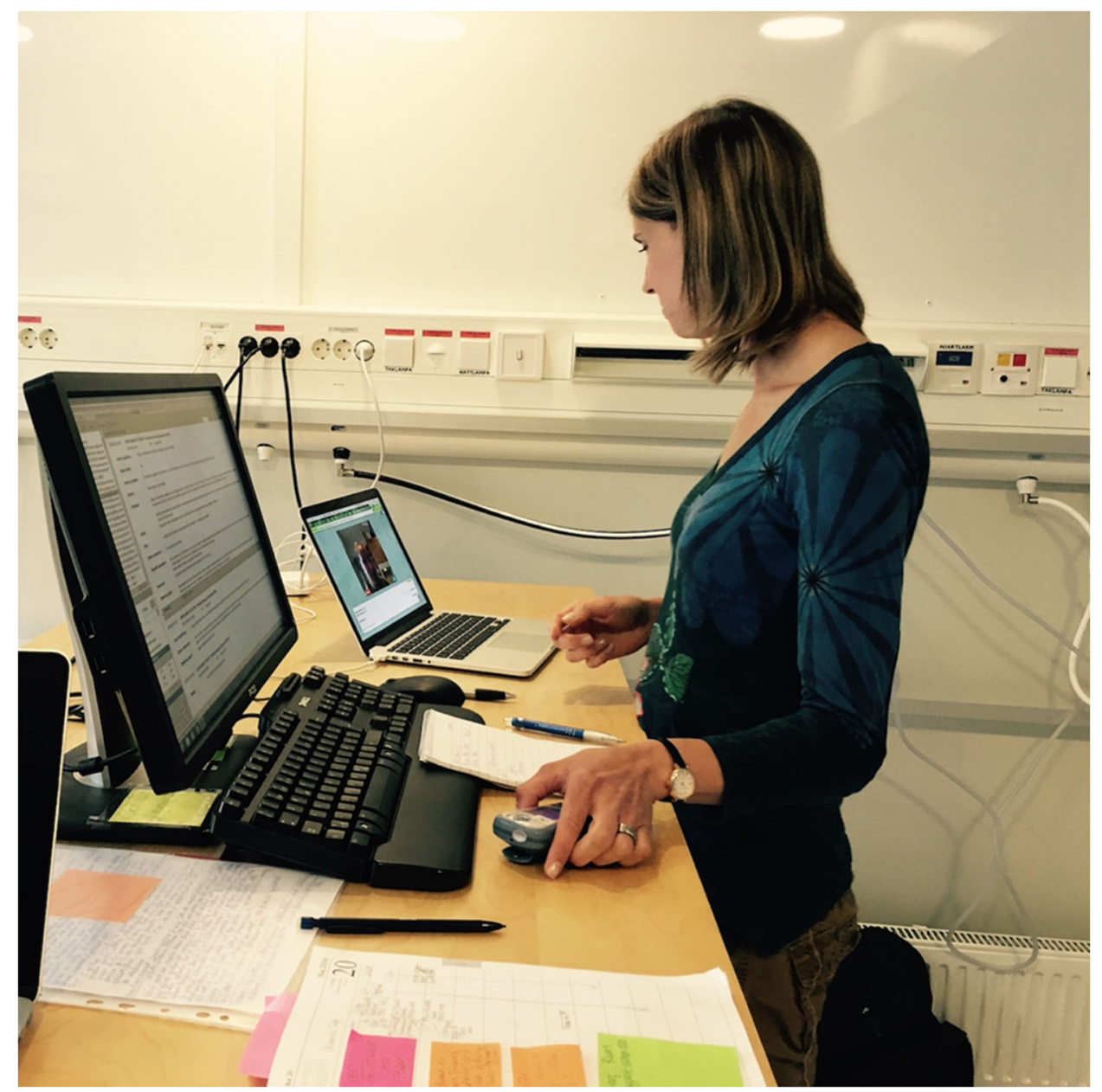

Figure 2. The view of the observer during video-mediated consultations. 
interview. The telephone consultations were recorded and transcribed and some were also observed from the nurses' side of the conversation, enabling the observer to see what the nurses were doing during telephone consultations.

The project structures included regular meetings over the course of three years between the clinical staff and the researchers, meetings that also inform this paper. The research team is multidisciplinary and includes researchers from informatics/ $\mathrm{CSCW}$, pedagogy, nursing, and medicine. The researchers met weekly through the course of the project (on Fridays, 40 min on average; some Friday meetings were cancelled). These were status meetings with the aim of informing and including everyone in the data collection and interventions. These meetings then informed the discussions during the regular larger project meetings, where the clinical staff and researchers met and collaborated.

The initiation of this study was genuinely collaborative. The clinical staff wanted to increase the reach and expand the practice of consultation and, after discussion, the video-mediated consultation tool was decided upon and then designed. The concrete problem was "discovered" by the practitioners, and agreed upon by the researchers (in line with what Avison et al. 2001 discuss in relation to action research). All research activities within the empirical setting focused on change through action as well as learning through reflection.

The empirical context for this paper is a clinic at a Swedish hospital. The following description is derived from the three-year engagement with the clinic. The patients come to this clinic after their fight with cancer is over. Some patients come often and some only once. The patients have all undergone treatment, some very extensive treatment with radiation therapy, surgery, and chemotherapy, while others have primarily received radiation therapy. The course of treatment depends on the stage and location of the cancer. The patients come to the clinic seeking help because of the complications linked to their cancer and their cancer treatment. The types of cancer that this clinic specializes in are cancers of the pelvic area, including ovarian cancer, cervical cancer, uterine cancer, endometrial cancer, colon cancer, and bladder cancer. Chemotherapy, surgery, and radiotherapy can trigger lifelong pathophysiological processes that can be handled as diseases in terms of diagnosis, alleviation, and treatment. Some are dealing with severe urinary leakage, and others have fecal leakage, varying in terms of severity. A large patient group is also, primarily or additionally, dealing with sexual problems. The sexual problems can usually be linked to complications from the radiation therapy.

As a background to the patient group, the clinic has been collecting extensive quantitative data (done by a survey with the purpose of both documenting the patient group as well as serving as a tool in the consultation) for years. The number of patients passing through the clinic varies from time to time, but the number of patients is around 200 per year. Over a thousand patients have participated in the survey. From this, the physicians leading the collection of that quantitative data have been able to estimate how many are dealing with the most severe complications. Of 390,000 cancer survivors in Sweden, there are approximately 18,000 dealing with 
fecal leakage, and 35,000 dealing with urine leakage. There are approximately 27,000 men and 20,000 women dealing with sexual dysfunction in Sweden alone. The numbers in Europe are (of a total of 20 million cancer survivors): fecal leakage: 1 million; urine leakage: 1.8 million; sexual dysfunction: 1.4 million men and 1 million women (Islind et al. 2019a, b).

The clinic has five staff members. Of these three are nurses, with one administrator and one physician. The three nurses have an academic education background, and are all licensed practical nurses and have specialization in oncology as well. Two nurses have been working at the clinic for years and have been active participants in the data collection informing this paper, while another nurse relocated (and has partly informed the research but is no longer working at the clinic) and a new nurse replaced that nurse. That is, there are thus a total of three nurses, but one nurse replaced another in the dataset. As mentioned, there is also an administrator working at the clinic, whose work includes filing the survey, which the patients fill out prior to their visits. The physician is specialized in oncology. In addition, there are other experts linked to the clinic that do not work there on a daily basis. Referrals can be made by the nurses and the physician at the clinic to these specialists, which include a dietician, a psychologist, a specialist in lymphedema, and other specialists that can help specific patients.

The aim of the clinic is to treat patients that are periphery to healthcare - that is, the patients are no longer patients in the traditional sense as they have been declared "healthy" because their cancer has either been removed or is in remission. They are, by medical definition, healthy. They do, however, struggle with the abovementioned complications. The complications for these particular patients, who have had cancer in the pelvic area, are hard to manage without knowledge of the problems and proper medication. These problems can render a person rather helpless as the symptoms are both limiting and taboo.

The clinic has a goal of maintaining a manageable number of patients on record. As stated earlier, the number of cancer survivors is increasing drastically, and to maintain a manageable workload, it is of great importance that the patients be informed about their own conditions and understand their "new normal" (where they learn to listen to their transformed body) and be able to make educated decisions about their self-care. The self-care aspect is important due to the notion that they have been declared healthy and thereby have scarce resources in relation to the healthcare system. At the clinic, the patient is part of a rehabilitation process that includes a survey and a consultation with a nurse in the form of face-to-face consultations, video-based consultations, and/or follow-up telephone consultations.

\section{Results}

The consultations have been a core practice at the clinic since the clinic was started up in 2012. In these consultations, the patient and the nurse meet, and this takes place at the clinic, face-to-face. The conversation is in the form of a meeting and includes a 
clinical consultation according to the nurse's education and years of experience in oncological cancer care. It is also a caring conversation in terms of its aim to be an empowering dialog (Islind and Lundh Snis 2017).

\subsection{The face-to-face consultation}

The face-to-face consultations are held in a closed room and the nurse and the patient are facing each other and discuss. The face-to-face consultation is usually one hour long and is always the first meeting between the nurse and the patient. This means that when that particular meeting is followed up either by telephone consultation after a few weeks (depending on the severity of the patient's problems) or by videobased consultation, the nurse and the patient have already met during the face-to-face consultation. This is an important aspect of the clinical practice and was nothing that "we," as researchers, designed into the change process of assisting with the introduction of alternative ways of conducting consultations; it was something that the nurses decided. They thought that establishing trust through a face-to-face relationship with the patients was important before continuing with the treatment, which could be conducted in various ways and by other means of meeting (such as telephone or video-mediated). Another important aspect of the "relationship" between the nurse and the patient is that during the whole treatment process, the patient has the same nurse treating them, so establishing trust is an important aspect of the nurse's practice and the patient's reality due to the complexity and type of the symptoms - which relate to intimate issues that some patients do not have the vocabulary to talk about, are not comfortable with articulating, or have hard time expressing - so establishing trust is key, according to the nurses.

Prior to the first consultation, the nurse reads through the patient's EPR, which requires experience in navigating the different types of records. Number of child births, smoking habits, other underlying physical diseases, psychological problems, earlier problems related to the stomach, cancer type, cancer diagnosis time, and cancer treatment type are examples of the relevant information nurses seek in the EPR. Information that sheds light on the possible damage that the cancer, and the subsequent cancer treatment, has caused is deemed relevant. While discussing the EPR and the selection of relevant information in an interview, one nurse stated: "If a patient has visited a dietitian during the treatment period, it tells me that it can be a sign that the patient has had a hard time already during the treatment and needs nutrition support." She would typically write about that in her preparation notes.

Out of the vast information in the EPR, about 50 words are written on an A4 paper (their preparation notes), including follow-up questions to be asked during the consultation. These preparation notes may look disorganized to the untrained eye; however, when the nurse explains the structure of the information on the paper, the notes are indeed precisely organized. During observations, the nurse reads aloud from the EPR and simultaneously writes in the preparation notes, condensing the long medical history into small notes: "smoked, stopped 1996; diabetes; bladder 
surgery 2001; cervix cancer; 50.4 Gy." To distill such a large amount of information, it is critical to identify the relevant pieces.

The survey that the patients answer prior to their first meeting at the clinic has been a part of the clinical practice since 2012 and consists of 182 questions. Before the consultation, the nurse scans through the survey and looks for answers that seem irregular compared to the information in the EPR or that shed light on new, unknown aspects. The questions cover the type of cancer, treatment, urine leakage, fecal leakage, urgency, sexuality, exercise habits, signs of depression, and quality of life. The nurse continues writing in the preparation notes, including notes such as "Rarely depressed" and " $5 / 7$ in anxiety." Hence, in this case, the patient is rarely depressed but is worried about a relapse. Notes such as "How does the patient handle urgency?" are also written. Many of the questions are formulated as "During the last six months, have you experienced..."; therefore, follow-up questions during the consultation are necessary to capture the patient's more recent state.

During the face-to-face consultation, the nurse goes through the answers from the survey together with the patient to form a joint picture of the patient's situation and to prioritize the symptoms together. The nurse also goes through the questions she has constructed in her preparation notes and poses follow-up questions. During the consultation, defecation frequency, stool consistency and urination frequency alongside aspects of urgency are covered. Stool consistency is relevant to the diagnosis and treatment plan. To identify consistency, the nurse shows the patient the Bristol Stool Scale (i.e., a scale used within healthcare to measure stool consistency), and they discuss the consistency in relation to the scale. The nurse asks: "What was your average number of defecations during the last few days?" The nurse must ask about quantity and quality of defecations several days after the actual experience. The patient tries to remember, and their discussion after a while leads to a measurement that can be documented. The nurse asks about specifics, such as smell, oiliness, and mucus. The patient answers and the nurse nods in an understanding way. Through the discussion, the nurse and patient typically discuss whether to increase the medication dose to decrease defecation frequency and to improve stool consistency. The nurse writes down the collective decisions to serve as a reminder to ask the physician to write a prescription. The face-to-face consultation is an important aspect of establishing trust as well as establishing a baseline of the patient's condition. When they have covered the most pressing issues, the nurse and the patient move towards discussing less urgent problems such as urinary problems, and finally they discuss sexuality.

The tools used in a face-to-face consultation are various clinical instruments, the Bristol Stool Scale being one such instrument which is brought into the discussion to form a shared view of the situation. Another instrument is the Visual Analog Scale (VAS) for pain, which is also introduced during the consultations (in those cases where the patient is dealing with pain). The survey is also a tool that is used actively alongside the preparation notes. These tools are actively employed to guide the consultation forward and increase mutual understanding. The clinical practice has 
also been using a mobile app as a tool for the patients to report patient generated health data (PGHD), and those data come into play during all consultation types. The impact of using the app to gather PGHD of the as well as the data work within the clinical context are reported elsewhere [blinded for review process].

\subsection{The telephone consultation}

The face-to-face consultation is, as stated earlier, usually followed up by a telephone consultation. The telephone consultations are much shorter than the face-to-face consultations, varying in length from five to $40 \mathrm{~min}$. The telephone consultation is a quick and efficient way for the patient to ask follow-up questions after the first faceto-face consultation and for the nurse to see whether the medicine doses are working or if there is a need for adjustment. The questions that the patients ask are often rather simple, such as: "The medication is not working; should I increase the dose?" And the questions that the nurses ask are often in terms of follow-up on specific aspects from the face-to-face meeting; such questions are suitable for a telephone call. Questions asked in such a consultation by the nurses can be: "We changed the dose of Inolaxol [a specific medication type] the last time we spoke, how is that working out? Has your frequency changed?"

The patients state that they are often met with an optimistic view from loved ones, in the form of congratulations that they have survived cancer, whereas few people are aware of the extent of their problems. They often feel guilty and fall back on: "I have survived. But I need to go to the toilet 20 times a day." However, in all their interactions with the nurses, regardless of consultation type, the patients do not have to feel pressure to feel lucky to be alive. According to one nurse: "They do not have to feel different here. We know everything. They can go to the toilet during the consultation." The nurses work primarily with helping patients that have undergone treatment for cancer in the lower abdomen with their treatment-induced problems, so the nurses are well aware of the problematic areas that the patients live with.

The following excerpt is taken from a telephone consultation where the nurse and the patient are talking. The excerpt is taken from the middle of the consultation to illustrate what type of difficulties not seeing the patient can trigger:

The nurse: "Where does it hurt?"

The patient: "It feels like it's in the bowel - there in the back. It feels like it's there."

The nurse: "I think it might be a little intergrowth [in the bowel], it can sound a little drastic, but it is a scar; then, after [the treatment], where there has been impingement, there is an inflammatory process, and that means when it heals, well, it becomes, like, rigid." 
The patient: "Ahaa. I feel like it felt like sometimes after I was pregnant as well, before I got sick, that it was like this."

The nurse: "That it could have been scar because of [the pregnancy]?"

The patient: "Can that be because of that as well then and that I feel that it has become worse now?"

The nurse: "Maybe. Yes. Well, that might be."

The patient: "Suddenly I'm like: God!!! I'm in so much pain now!"

The nurse: "Okay. Well, all pain is some kind of signal of: 'something is wrong here'; or we interpret pain like that. But you can also get phantom-pain or pain that is triggered by you having had more pain in periods in that location. Like flares. Then it can trigger the system, and the pain can increase."

When the nurse and the patient are not able to see each other, things such as the locations of the pain are hard to describe and requires extensive effort to explain. The excerpt starts off with a negotiation of the location of the pain area and then ends with the nurse explaining how pain functions in the body of a patient that has had cancer and extensive cancer treatment in the lower abdomen. In this particular example, it would have been better if the patient could have pointed to the pain area, which would have required fewer words. The explanation of how pain works would most likely have been the same, but the location is easier to point to than to guess when dealing with locations that are inside the body.

The nurses were able to multi-task during telephone consultations which was seen during observations and the patients were also able to do so. During interviews with the patients they did however not emphasize that but did identify that they needed to verbalize their pain areas, which is consistent with the material transcribed from the consultations. It would have been interesting to observe the patients during the telephone consultations but due to the fact that some patients were located at work during the telephone consultations it was not possible. The lack of observations of the patients' side was compensated with interviews afterwards where the patients identified the verbalization aspect.

\subsection{The video-based consultation}

Some patients need to travel hundreds of kilometers to the clinic - with their aforementioned symptoms of urgency - making travelling much harder. Because of this, video-based consultation was developed as an alternative way of conducting the consultation, where the patient can stay at home but are still able to see their 
nurse. However, the video-mediated consultations have so far only been conducted with patients that the nurses have met at least once in a face-to-face consultation before (as said earlier). This means that the rich caring relationship is not forming through video but is rather a way of continuing the richness of the face-to-face consultation.

The video-based consultation tool is not meant as a replacement of any kind but rather as a complementary practice when follow-up telephone consultation is not feasible and the face-to-face consultation cannot take place due to urgency issues or travel distance. The video-based consultation tool is a Skype-like meeting with sound and video through an encrypted connection due to sensitive patient data. While engaging in the video-based consultation, the patient and nurse can also share text and links via a text chat. The text chat was introduced to enable a simple sharing tool. The findings from the video-based consultations suggest that videoconsultations tend to last longer and are more intimate in terms of the details of the symptoms.

The patients tend to like the video-based consultations:

"I think it's awesome and very good, because then you do not, what can I say, when you don't have to meet - then you just turn on the computer. Then there is no travel time involved."

Another patient said:

"Well yes, I thought this was good, nice solution. People are not always able to travel to the clinic and then the telephone is really good; however, it is like another kind of contact when you are able to see each other. I thought it was good especially for us patients who cannot get away from home."

One patient reflected on how the video-based consultation differs from the face-toface consultation that she had before the video-mediated consultation:

"I do not feel that it is any different except for the fact that I did not touch her; I usually hug her (patient laughing). This is much better than just talking on the phone."

The same patient continues:

"If you do not have a physical examination and the consultation is just about talking, this is a good way. I can absolutely meet via by video again." 
Another patient was a bit more critical and also reflects on the difference between the video-based consultation and the face-to-face consultation:

"The difference between a regular visit and this is that I get to skip the trips to the hospital. But at the same time, I also work in [the city where the hospital is] five days a week, so there's no big difference for me really. But at the same time it is very easy to do this, so you skip the commute to the hospital. So there's that. But it feels like it works like a telephone call with the nurses. Really no big difference for me. However, the technology did not obstruct anything, it was just as it is usually with [the nurse]."

About using technology as a means of conducting the consultation she continues:

"It was a bit strange at first because this was the first time, but because I now know how it works, it's no problem at all next time. I see no challenges with this even though I'm not used to Skype, but I have no problems with the technology. You must stay up to date when you have two teenagers. I'm a mother who keeps track of what they do online and what they're talking about and so, I don't have any problems with that technology. So, the technology is really no problem."

Even though she sees no problems with the technology itself, and the consultation and the conversation were good, she reflects on the video feature:

"Even so. I think it's a bit hard to see myself in a picture there. What irritates me is that I'm so extremely tiny still [after cancer treatment], so I just look like a big stick with a head on it."

She expresses sadness but then says:

"Well, Well. You just have to stay positive."

The video-mediated consultations allow for the patient to show where the pain is located, whereas the telephone consultation lacks this visualization aspect (as seen in the example where the nurse and the patient debate the pain location). The observations from video-mediated consultations show that the video allows for a more expressive description of pain and other experiences, which has similarities to the face-to-face consultation. Much of the nurses' skills are, according to the nurses, connected to their visual estimation; they know the pain scale, and sometimes merely seeing the patient reveals much more than words ever do. It reveals pain, it reveals 
weight loss, and the color of the skin can indicate various things relevant to the nurses' assessment of the patient's condition.

The video-based consultation is a digital tool that alters the interaction somewhat in comparison to the face-to-face consultation. The nurse becomes aware that she has to be more explicit about what she is doing during the video-based consultation due to the importance of the awareness aspect discussed in the introduction. The patient cannot be aware of what is happening to the same extent that he/she can in the faceto-face consultation. The nurse explains that in telephone consultations she does not feel the same need to involve the patient in her actions at her end. She can scribble and do other things, whereas during the video-based consultation, there is a need to involve the patient to a larger extent due to the fact that the nurse has to change screens (which influences eye contact). During the consultation, for example, the nurse says: "Now, I'm looking in the [EPR], that's why I'm not looking at you now."

\subsection{The three consultation types}

The consultation is, as stated earlier, the core of the nurses' practice and a core aspect of the care from the patient's point of view. In the consultation between the nurse and the patient, the focus is initially on how the patient feels right then, in relation to their symptoms. Based on the survey (which will be elaborated on below), the nurse follows up with questions to further clarify the symptoms so as to make a diagnosis. According to the nurses, they are also there to support the patient in taking her medicine, doing her exercises, and eating according to the plan - that is, to encourage the patient to adhere to the rehabilitation plan. During all consultation types, the patient gets the opportunity to review their symptoms, experiences, fears, and concerns with someone who has extensive experience of patients with similar symptoms. This is central from a psychosocial point of view. Both patients and nurses confirm that the caring conversation plays an important role in decreasing the patient's anxiety by the nurse responding to questions and acknowledging the patient and their problems. According to the patients, it is extremely valuable to finally encounter someone (regardless of consultation type) who understands and takes the time to listen without passing judgment. During the video-based consultation, the nurse says in a trusting voice: "It will never be just as it was before the treatment, what has been done cannot be undone."

During both telephone consultations and video meetings, the nurses take notes on paper (the preparation notes). No entries are made in the EPRs during the call, but, according to the nurses, it facilitates the consultation and provides security to have the record available to read. During the face-to-face consultation, the nurse does not use the EPR as a working tool, making the structured preparation notes even more important. However, during the video-based consultation, and the consultations via telephone, the nurses can rely on the EPR for backup and support, making it a valuable tool in these two forms of consultation types. After the call, the nurse 
documents the symptoms, prescriptions, and medications for the physician to approve and adds reports in the EPR.

The consultation types also require different types of administrative processes. The face-to-face consultation requires planning weeks ahead, the patient has to come to the clinic, and the nurse has to have time in her schedule. The video-based consultation requires less planning as it can be scheduled a relatively short time in advance; the patients simply have to sit down with a computer (or a smartphone) and turn on their video. And a follow-up telephone consultation does not have to be scheduled at all; the nurse can call the patient without having booked a consultation beforehand, and the patient can likewise call the nurse.

After a few video-based consultations, during an interview, the nurses reflect on the associated technology: "So I see the pros and cons of the video. I see as a great advantage about having video consultation [...] I think like this: when I call the patient, they say, oh, now I'm at work, I will close the door, and then we can talk. However, the video consultation is prescheduled, and they skip commuting here."

The nurse continues to reflect upon the qualities of using video:

"I think it's very important to see the person. Because I can see if she looks tired; I can see if she looks happy. I can look at facial expressions when she's talking. But, as I said, when you're home, I think they may think [the nurse] is coming into their homes, maybe not everyone likes it. I think that when we talk to them via telephone they may be at home walking around with their diaper-sweatpants, they have no make-up on, and have messy hair. They have not tidied themselves. But when I have video consultations with them, I think a lot of them fix themselves up, like if they were going to a physical meeting. Then I think, I think, will it be a small obstacle for them that we are coming into their holiest place and that they also need to get ready? Otherwise, I would have just called via telephone, and they could sit in their place and not have to wash themselves. I think in the worst case scenario that it can be like that. I think it may be an 'Achilles heel.' And then I think it may be, uhm, that I'm still not comfortable with the camera. I'm still so, so, should I be like this? When I stand and the screen is here, then I am thinking, I look like this, and I'm not comfortable at all."

The nurse reflects on the difference between the face-to-face consultation and the video-based consultation:

"It's also an important aspect, when I sit in a physical consultation [face-to-face consultation], I look down at the paper and look at her. With this [the video-based consultation], I look at the journal, I look at her, I'm looking at the paper. So it's less. I have less eye contact with her via a video chat than at a physical meeting. 
But I think that's just a matter of establishing a habit. I'm not used to it, because I have not had that many yet. I facetime occasionally with my friends. But I just have to work on that to get used to it. I think it's a really good complement, but I do not think it will be able to replace the physical meeting in all contexts. And from that perspective I think it's good. As a complement. And the more you get into used to how it works technically, everything gets easy. I mean, during the first video consultation it took 25 minutes to get it rolling. Neither me nor the patient has time for that. But then, these times after, it's just click on the button and log in, and boom. Then that's amazing."

About the difference between the video-based consultation and follow-up telephone consultation another nurse says:

"This, which I think is a positive aspect, even though it's a small screen, I could just pick up a paper and point. I could use [drawings and clinical instruments]. And I cannot do that during a telephone consultation. That advantage I think is really good. Also, if I'm talking to someone and need to look at them, I'm much more present in the conversation than if I'm on the phone. I do things. I am drawing on paper. I do everything. But doing this I need to sit in front of the screen, so I'm just thinking about the moment, and what we are talking about."

During a video-based consultation a patient excused herself and left in the middle of the consultation to go to the bathroom. When talking about the patient leaving in the middle of the video-based consultation the nurse involved says:

\footnotetext{
"What we could do is use this with those patients who have extreme stomach problems. Like when she left. She just said, I have to go to the toilet. Yes, absolutely I said. And then she walked in [to the bathroom] and closed the door. I mean, if you have a patient who has acute problems, maybe they may need time, but some just go in and out [of the toilet] and then they should be able to leave during the call and if they need, they can be off for five minutes. I can start working on other things. I can prepare, or I can start writing in the journal. I do not have to lose time, and they can feel confident that they can go to their own toilet. And I could even say like: take it easy now, I can do something else here, so they do not need to feel that it's any stress and then they can relax."
}

Due to the problems that these patients have, for instance, not being able to control their bowel movements or urination or dealing with constant pain, the video-based consultation has enabled them to be in the privacy of their own home during the consultations. The nurses were quite nervous about this enhancement of their practice, and they had low expectations for it working out. The nurses thought that 
the patients would feel exposed in a way. One nurse said before a video-based consultation: "The patient will probably feel the need to put on make-up and tidy up before I call." However, the patients did not do that. Patients have invited the nurse into their kitchen with dirty dishes, and two patients had their children nearby. They excuse themselves and run to the toilet in an ongoing video-mediated consultation, which they do not do at the clinic when they have a face-to-face consultation.

What patients have also done during the video-mediated consultations is point to the areas of pain, meaning that they use the full potential of the technology. However, they cannot make physical contact - which one patient commented on, saying that she usually hugs [the nurse] during the consultations (referring to face-to-face consultations). What was most surprising, however, was one patient that had been a part of the clinical practice for years who opened up tremendously to the nurse, stating afterwards that she was so comfortable that "something just happened" and she told the nurse everything - information that she had been withholding for years that was most definitely a deeply buried source of problems affecting her progress. In this particular consultation, the ability to stay at home most definitely had an influence on the patient's healing progress.

\section{Discussion}

Since the emergence of telecare, researchers across a range of disciplines have taken a keen interest in its evolution and the adoption of its medical and caring potentials, whereas the focus is now shifting toward understanding the potentials of telecare as an integrated part of work and the potentials for the clinical staff in combination with the potentials for the patients. In this paper, the analysis of the increased digitalization of what we call the "virtual clinic" has focused our attention on the interaction between the actors within the practice of consultation and the specific functionality afforded by the mediation of three types of consultation. We take a socio-technical and practice perspective on affordances and include the complementary activities and support tools in the consultation to understand the relationship between the actors and the resources and capabilities in the situated consultation practice.

Despite the extensive literature and different streams of research on affordances, we found the theory difficult to apply when the actors are heterogeneous. We could have reduced the complexity and merely looked at the nurses' affordances in relation to the tools used during a video-mediated consultation, but we wanted to understand the reality at the clinic as it is, where the consultation is a complex practice including heterogeneous actors (patients and nurses), where the practice is mediated in a multiplicity of ways, and where analog and digital tools are used in combination. Hence, there are many co-existing resources and clinical tools that contribute with continuous information, which can be further fed back into the situated interaction. Similar findings were reported in Shoebotham and Coulson's (2016) studies, where they study both the uses and effects of the engagement of an online support community in terms of "therapeutic affordances." What distinguishes our case is 
that the outcome of one interaction may result in new ways of behaving and working, both for the patients and the nurses in the consultation practice.

Much insight can be gained from studying the body of platform research as successful platforms with a significant digital element tend to fall into the category of two-sided or multi-sided markets, where the platform brings parties together in open co-creation arrangements (Boudreau and Lakhani 2009) and the two, or multiple sides can vary extensively; they can be heterogeneous but still be a part of the same platform (Islind 2018). Such platform arrangements are based on the exposure of APIs and the sourcing of SDKs and rely on standard Internet technologies for the development of new services. The two-sided or multi-sided market perspective on digital platforms allows for an intermediary boundary spanning actor groups such as suppliers and users (Furstenau and Auschra 2016; Islind 2018; Rochet and Tirole 2003; van Astyne et al. 2016).

The relevance of this literature within CSCW can be questioned and highly criticized, but our intention is not to elaborate on that literature; we are, however, inspired by the notion of two-sidedness as well as multi-sidedness. In the case presented in this paper, there are two-sides from that we draw the notion of twosided affordances. As we see it, the notion of two-sidedness can be applied on affordances, and if a case has three heterogenous actors, the affordances can be multi-sided, and based on that argument, we therefore want to offer the extended lens of affordances, which we call two-sided affordances as the main contribution of this paper. Affordance is always in close relation to a user or an actor, and throughout the literature, more often than not, in relation to a single actor and singular activity (Bardram and Houben 2018). This is understandable since Gibson's original concept focuses on individual conceptions and Norman's (1988) extension of affordances, as well. Our struggle, however, within this particular complex practice of consultation, has been to research affordances in a heterogeneous context. What we want to discuss by bringing in the two-sided-ness into the community of CSCW is therefore the possibility of affordances being two-sided or multi-sided. Two-sided affordances can include affordances of tools in a practice that has heterogeneous actors. The affordances are, in that sense, different for to the different "sides" of the practice. As mentioned earlier, our argument extends to multi-sided affordances even though this particular case has two-sided affordances. As we stated in the theory section, we argue that the actualization of affordances is genuinely related to the practice situated and embedded in the use of the particular technology or tools and might in turn lead to the identification of new affordances in terms of capabilities. This understanding is in line with the understanding of collaborative affordances, which is defined as allowing for collaborative action in relation to an artifact between a set of actors within a specific context (Bardram and Houben 2018). The understanding takes the lens of affordances further, from the single actor and single activity way of thinking; however, this understanding is not sufficient for all contexts, which is why we extend that notion of affordances with the multi-directional and socio-technical relationship between the technology (both analog and digital) and the practice and shed light on 
the two-sidedness that we see herein due to the heterogeneity of the actors (and tools where some are shared and some not) on the "different sides" of the consultation.

Here we wish to conceptualize the affordances found while using the tools in the three consultation types and illustrate their multi-sidedness in line with the discussion above. Each consultation type is filled with different tools, which are either digital or analog. The affordances of these tools (in each consultation type) together are summarized in Figure 3 below, which is an attempt to illustrate the consultation types.

We argue in line with others that affordances are relational and emerge through interaction between the actors and their surrounding artifacts (Van Osch and Mendelson 2011) and exist relative to the action capabilities of a particular actor (McGrenere and Ho 2000), but we extend that notion to also include complex settings, with the notion of two-sided and multi-sided affordances. The multiplicity and diversity of the socio-technical view includes many resources that can be a part of a mediation in a two-sided way.

To explain further, we aim to offer some examples and a deeper discussion of what we mean. In line with Gibson's (1977) definition of affordances, the possible actions in the consultation are dependent on the "environment" of the consultation. The video-mediated consultation has, in that sense, affordances other than the two other types of consultations. For instance, due to the particular problems that the patients have, such as not being able to control their bowel movement or urination, the videomediated consultation afforded them the privacy of their own home during the consultations, where the patients had their own toilet setup (one patient had customized the bathroom at home with a small chair to put their feet on during toilet

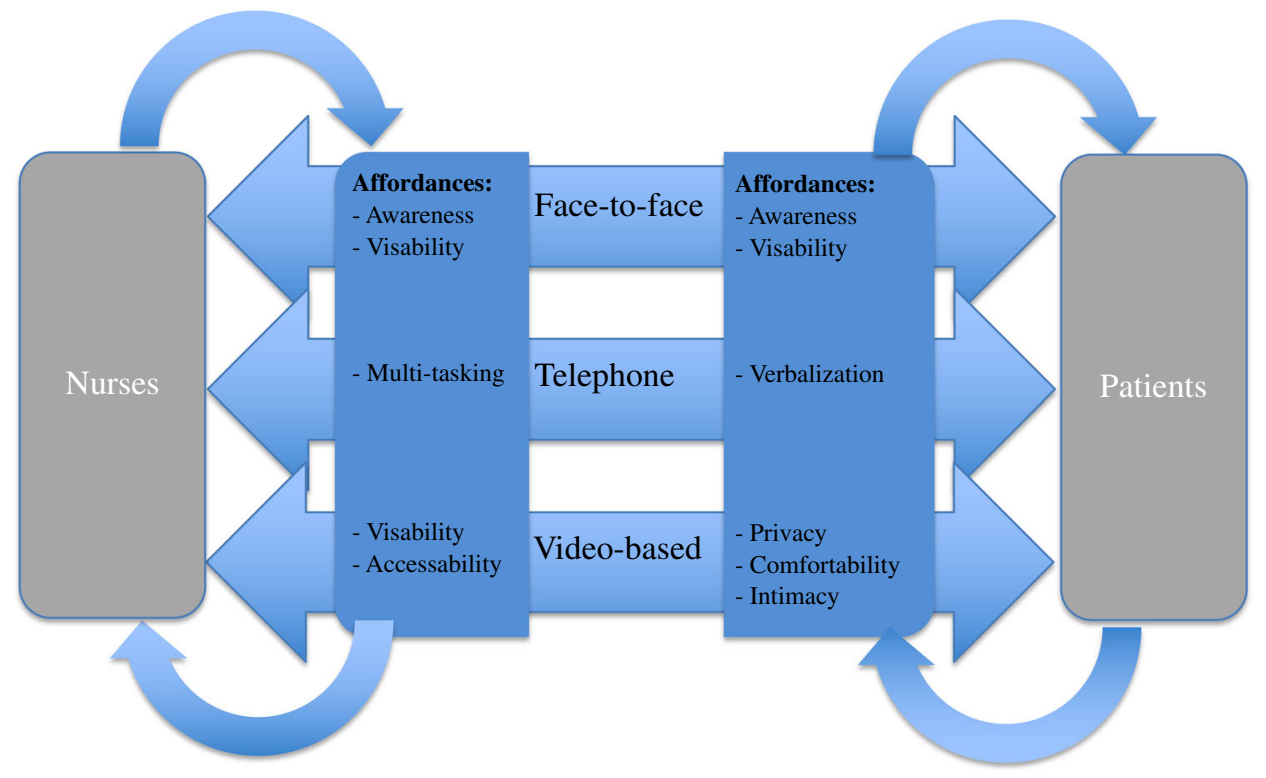

Figure 3. The affordances in relation to the consultation types 
activities to decrease the stress on the pain area of the bowel). The notion of the patients being at home had initially made the nurses quite nervous. However, the patients did not do that. Patients have invited the nurse into their kitchen with dirty dishes, and two patients had their children nearby. They excuse themselves and run to the toilet in an on-going video-mediated consultation, which they do not do at the clinic during a face-to-face consultation. The face-to-face consultation has its own important qualities, and important one being awareness, which has associated with it a well-known debate within the literature (cf. Greenberg and Gutwin 2016). But what was interesting was when one patient, who had been a part of the clinical practice for years, opened up immensely during a video-based consultation, letting the nurse "in" in a way that she had not done before, stating afterwards that she was so comfortable during the video-mediated consultation from home that "something just happened."

In these cases, where the patients have problems that hinder them from commuting, the notion of comfortability when staying home, has thereby had an influence on the degree of relaxation and sharing during the consultation for the patient (one side). The video-mediated consultation and the comfort of their own home enriched and empowered the patient in the particular example above. The comfortability aspect extends mostly to the patients as the nurses (the other side) felt some discomfort in relation to the camera in the beginning. The affordance of comfortability (which we herein choose to call it) affords the patient to be comfortable (in relation to the technology as well as space, in a socio-technical manner), but not the nurse, in relation to the video as such. However, the nurse can use her visual skillset during the video-mediated consultation and afforded increased accessibility - the use of her EPR - increasing other aspects of practice related to comfortability aspects and decreasing the need for preparatory work before the consultation (e.g., reference blinded for review process). The comfortability affordance is therefore in itself a complex notion. Another example of the complexity is that the telephone consultation affords comfort in a different way in comparison to the video-mediated consultation. The telephone consultation is convenient for the patient as she can take the call at work, and, for the nurse, it requires no planning ahead and affords simultaneous actions for both actors. However, it requires a level of vocabulary from the patient to explain pain and its locations, and the nurses visual skillset does not come into full use. As we see it, collaborative affordances, and affordances in a practice, are hard to pinpoint and hard to actualize to the extent that they are applicable to complex practices.

This particular affordance is thereby two-sided. It is neither a two-sided or multisided market nor platform, but it is, however, a two-sided affordance. The notion of affordances is, as we see it, closely linked to the notion of practice. It is, however, not inherently easy to distinguish collaborative affordances that benefit all actors in a practice at the same time. The affordances lens and the practice lens fit seemingly well together, and collaborative affordances sound magical; however, when it comes to complex practices that involve heterogeneous actors, it is harder to identify collaborative affordances, especially at a distance. When actors closely co-exist in 
a particular practice, but have heterogeneous needs, we argue that their affordances can thereby be two-sided. Leonardi (2011) argues that the actualization of affordances may also result in functional constraints and that the impact of the actualization is not a one-stop phenomenon but rather a continuous process of appropriation of material properties and organizational/human routines to meet the desired outcome. However, when affordances extend to a part of a practice, the complexity grows. The marriage between affordances and the practice lens is a rather complex one, and we therefore wish to extend the scope with the notion of two-sided or multi-sided affordances. In this paper, we do, however, also want to problematize and lift the different types of affordances that this paper offers for both "sides" of the practice.

What we see from our case is that the affordances differ, depending on the actor involved (thereby the two-sided affordances discussed above), but we also see that the affordances differ depending on the consultation type. The practice of consultation, which is shared between the nurses and the patients, is a complex practice that is now being virtualized to a video-mediated consultation complemented with a telephone consultation, but an important aspect is that the three consultation types are not seen as interchangeable - they co-exist as a part of the clinical work and are complementary to each other and can be viewed as an augmentation and not as a replacement. The consultation practice has been enhanced by the introduction of new tools. The nurses have become aware of factors that they had not reflected upon earlier, such as the notion of an "unknown audience" (Marwick and Boyd 2011), where the nurses are unsure who is listening to the consultation. The nurses have, however, not reflected upon the unknown audience of the telephone consultation, which can easily be put on speaker, nor the possibility that the patients can record the face-to-face consultation on their phones. The way the nurses and the patients compare the consultation types in their quotes in the results section stems more from the fact that they want to understand the differences in the consultation types, and the comparison comes from their curiosity in what is lost and what is gained. The faceto-face consultation and telephone consultations have been a part of the clinical work for so long whereas the tools that represent change, e.g. video-based consultation tool are contrasted with what is rooted in the previous way of working.

The face-to-face consultation is in line with collaborative affordances, where there are more shared interests of collaboration that are mediated by the tools used in the practice. What we have found is that the consultations at a distance are more twosided, where the affordances between the participants are not as aligned. In line with Gawer's (2014) definition of a platform being two-sided or multi-sided when the platform facilitates an exchange between consumers that have not been in transaction before and that the two-sidedness enables interaction, we argue that is the reason why the video-mediated consultation and the telephone consultations have two-sided affordances, which vary between the actors involved. The digital technology (for instance the video) affords increased comfort for the patients and multimodality for the nurses in the practice even though the interaction was possible before (during 
face-to-face consultation) the consultation is enhanced by these affordances. The two-sided or multi-sided affordances, apply when heterogeneity is detectable in the practices involved and we offer that as an extension of the affordance literature. Moving forward with this type of research, future work could include i) analyzing cases with multi-sided affordances, ii) analyzing other contexts than healthcare where two-sided or multi-sided affordances can be detected as well as iii) analyzing the twosidedness or multi-sidedness of the practice lens.

To sum up the practical implications of this paper, the patients in this case have little time with healthcare professionals due to the fact that they been declared "healthy" (even though they are still dealing with treatment-related symptoms), making it all the more important that the time they get is of high quality. In this case, the face-to-face consultation has been crucial for establishing the caring relationship at the beginning. After that, the video-based consultation enables the patients to skip the commute, use their own facilities, and open up more about intimate issues as well as use the full extent of the video by pointing to their pain area. In the telephone consultation the patients were able to skip the commute as well but had to verbalize their pain without visual confirmation by the nurse. What the results show, in regard to the telephone consultation, is that a certain vocabulary level alongside the ability to externalize and verbalize the symptoms was a crucial factor when communicating difficult symptoms, such as pain, due to the lack of visual confirmation. Some patients are truly knowledgeable in regard to their own care, whereas others are not as verbal, and those differences were less visible in the video-mediated consultation and face-to-face consultation, where awareness, visual contact, and a wider spectrum of the nurses' skillset come into use. What we conclude in regard to video as a factor is that seeing each other and being able to connect visually is important. Consequently, what we see is that the consultations after the first consultation can be conducted via video, whereas quick questions and follow-ups can be done by telephone. When choosing a consultation type, the complexity of the problems that are to be discussed in the consultation needs to be considered; if the visual skillset is needed and the patients have complex problems, video-based consultations are the type that works best, especially for those unable to commute.

\section{Conclusion}

Telecare has the potential to increase the quality of care while also decreasing costs. However, despite great potential, efficiency in care practices and cost reduction remain hypothetical. In this paper we focused on the essential qualities of i) face-to-face consultations, ii) video-based consultations, and iii) telephone consultations and shed light on their affordances. From our case, we extend the lens of affordances to include a socio-technical view on affordances and suggest two-sided and multi-sided affordances for practices that include heterogeneous actors and a variety of tools. We define two-sided, and multi-sided affordances as a socio-technical view on affordances that allows for the different "sides" to have different affordances and be dependent 
upon different tools. The choice between two-sided or multi-sided depends on how many heterogenous actors are involved; in cases where the heterogenous actors are two, the notion of two-sided affordances can be applied but where the heterogenous actors are three or more, the notion of multi-sided affordances can be applied. What we have illustrated is that some affordances extend to specific actions and can be liberating for one side of the practice but afford constraints for the other side of the practice and in this particular paper we have illustrated two sides. We have demonstrated that the understanding of collaborative affordances is not enough when it comes to explaining complex practices made up of heterogeneous actors and therefore want to extend that lens of affordances to include two-sided and multi-sided affordances. Two-sided and multi-sided affordances are views that can be used where the affordances differ between the actors, whereas collaborative affordances can apply when affordances are shared between both actors within a practice. The contribution is also illustrated in a set of two-sided affordances, exemplified from our case, and we offer an understanding of the kind of situations in which each consultation type is fruitful. The affordances presented do not comprise an exhaustive list but still offer an exemplary representation of how two-sided affordances can be visually conceptualized from a two-sided or multi-sided affordances view, based on the findings in the consultation practices of the chronically ill. Viewing the practice as a whole, and the affordances as two-sided allowed us to look into how the different consultation types can benefit patients in different ways as well as increased our understanding on the effects of the virtualization of clinical work for the nurses. The differences in affordances for the two sides (the patients vs. the nurses) are an important aspect for understanding the complexity of heterogeneous actors co-existing in multi-faceted practices with a set of analog and digital tools. Even though this particular paper presents a case with two-sided affordances, the extension can be applied to cases with three or more sides, and then called multi-sided affordances. Our future work includes further investigations of twosided and multi-sided affordances, and we would hereby like to invite others to join that mission.

Open Access This article is distributed under the terms of the Creative Commons Attribution 4.0 International License (http://creativecommons.org/licenses/by/4.0/), which permits unrestricted use, distribution, and reproduction in any medium, provided you give appropriate credit to the original author(s) and the source, provide a link to the Creative Commons license, and indicate if changes were made.

\section{References}

Andersen, Tariq O.; Jørgen P. Bansler; Finn Kensing; Jonas Moll; Troels Mønsted; Karen D. Nielsen; ... and Jesper H. Svendsen (2018). Aligning Concerns in Telecare: Three Concepts to Guide the Design of Patient-Centred E-Health. Computer Supported Cooperative Work (CSCW), vol. 27, no. 3-6, pp. 1181-1214. 
Archer, Norman; Urslin Fevrier-Thomas; Cynthia Lokker; K. Ann McKibbon; Sharon E. Straus (2011). Personal health records: a scoping review. Journal of the American Medical Informatics Association, vol. 18, no. 4, pp. 515-522.

Avison, David; Richard Baskerville; and Michael Myers (2001). Controlling action research projects. Information Technology \& People, vol. 14, no. 1, pp. 28-45.

Bardram, Jakob E.; and Claus Bossen (2005). A web of coordinative artifacts: collaborative work at a hospital ward. In GROUP '05. Proceedings of the 2005 international ACM SIGGROUP conference on Supporting group work, Sanibel Island, Florida, USA, 6-9 November 2005. New York: ACM Press, pp. 168-176.

Bardram, Jakob E.; and Steven Houben (2018). Collaborative affordances of medical records. Computer Supported Cooperative Work (CSCW), vol. 27, no. 1, pp. 1-36.

Barley, Stephen R.; and Gideon Kunda (2001). Bringing work back in. Organization science, vol. 12, no. 1, pp. 76-95.

Bartel, Caroline A.; and Raghu Garud (2003). Narrative knowledge in action: Adaptive abduction as a mechanism for knowledge creation and exchange in organizations. The Blackwell handbook of organizational learning and knowledge management. Malden: Blackwell, pp. 324-342.

Bechky, Beth A (2003). Sharing meaning across occupational communities: The transformation of understanding on a production floor. Organization science, vol. 14, no. 3, pp. 312-330.

Benbasat, Izak; David K. Goldstein; and Melissa Mead (1987). The case research strategy in studies of information systems. Mis Quarterly, vol. 11, no. 3, pp. 369-386.

Boland, Richard J.; and Ramkrishnan V. Tenkasi (1995). Perspective making and perspective taking in communities of knowing. Organization science, vol. 6, no. 4, pp. 350-372.

Boudreau, Kevin; and Karim Lakhani (2009). How to manage outside innovation. MIT Sloan Management Review, vol. 50, no. 4, pp. 69-75.

Bradner, Erin (2001). Social affordances of computer-mediated communication technology: understanding adoption. In CHI'01. Extended abstracts on human factors in computing systems. Seattle, 31 March - 5 April 2001. New York: ACM, pp. 67-68.

Bradner, Erin; Wendy A. Kellogg; and Thomas Erickson (1999). The adoption and use of 'Babble': A field study of chat in the workplace. In ECSCW'99. Proceedings of the 6th European Conference on Computer Supported Cooperative Work, Copenhagen, Denmark, September 12-16, 1999. Dordrecht: Springer, pp. 139-158.

Brown, John S.; and Paul Duguid (2001). Knowledge and organization: A social-practice perspective. Organization science, vol. 12, no. 2, pp. 198-213.

Cabitza, Federico; and Carla Simone (2012). Affording mechanisms: an integrated view of coordination and knowledge management. Computer Supported Cooperative Work (CSCW), vol. 21, no. 2-3, pp. 227-260.

Carlile, Paul R. (2002). A Pragmatic View of Knowledge and Boundaries: Boundary Objects in New Product Development. Organization science, vol. 13, no. 4, pp. 442-455.

Carlile, Paul R. (2004). Transferring, Translating, and Transforming: An Integrative Framework for Managing Knowledge Across Boundaries. Organization science, vol. 15, no. 5, pp. 555-568.

Chen, Yunan (2010). Documenting transitional information in EMR. In SIGCHI 2011. Proceedings of the SIGCHI Conference on Human Factors in Computing Systems, 7-12 May 2011, Vancouver, Canada. New York: ACM Press, pp. 1787-1796.

Chiasson, Mike; Madhu Reddy; Bonnie Kaplan; and Elizabeth Davidson (2007). Expanding multidisciplinary approaches to healthcare information technologies: What does information systems offer medical informatics?. International journal of medical informatics, vol. 76, pp. 8997.

Dedding, Christine; Roesja Van Doorn; Lex Winkler; and Ria Reis (2011). How will e-health affect patient participation in the clinic? A review of e-health studies and the current evidence for changes 
in the relationship between medical professionals and patients. Social science \& medicine, vol. 72, no. 1 , pp. 49-53.

Dourish, Paul; and Victoria Bellotti (1992). Awareness and coordination in shared workspaces. In CSCW'92. Proceedings of the 1992 ACM conference on Computer-supported cooperative work, 1-4 November, Toronto, Canada. vol. 92, no. 3, pp. 107-114.

Eaton, Ben; Silvia Elaluf-Calderwood; Carsten Sørensen; and Youngjin Yoo (2015). Distributed tuning of boundary resources: the case of Apple's iOS service system. MIS Quarterly: Management Information Systems, vol. 39, no. 1, pp. 217-243.

Evans, David S. (2003). Some Empirical Aspects of Multi-Sided Platform Industries. Review of Network Economics, vol. 2, no. 3, pp. 1-20.

Fitzpatrick, Geraldine; and Gunnar Ellingsen (2013). A review of 25 years of CSCW research in healthcare: contributions, challenges and future agendas. Computer Supported Cooperative Work (CSCW), vol. 22, no. 4-6, pp. 609-665.

Furstenau, Daniel; and Carolin Auschra (2016). Open Digital Platforms in Health Care: Implementation and Scaling Strategies. In ICIS 2016. Proceeding of International Conference on Information Systems, Dublin, Ireland, 11-14 December 2016. AIS eLibrary. pp. 1-18.

Gaver, William W. (1991). Technology affordances. SIGCHI 1991. In Proceedings of the SIGCHI on Human factors in computing systems, 28 April - 5 June 1991, New Orleans, Louisiana. New York: ACM, pp. 79-84.

Gawer, Annabelle (2014). Bridging differing perspectives on technological platforms: Toward an integrative framework. Research Policy, vol. 43, no. 7, pp. 1239-1249.

Ghazawneh, Ahmad; and Ola Henfridsson (2013). Balancing Platform Control and External Contribution in Third-Party Development: The Boundary Resources Model. Information Systems Journal, vol. 23, no. 2, pp. 173-192.

Gibson, James (1977). The theory of affordances. In Robert Shaw and John Bransford (eds): Perceiving, acting, knowing: Toward an ecological psychology. Hillsdale, New Jersey: Lawrence Erlbaum, pp. 67-82.

Graneheim, Ulla H.; and Berit Lundman (2004). Qualitative content analysis in nursing research: concepts, procedures and measures to achieve trustworthiness. Nurse education today, vol. 24, no. 2, pp. $105-112$.

Greenberg, Saul; and Carl Gutwin (2016). Implications of we-awareness to the design of distributed groupware tools. Computer Supported Cooperative Work (CSCW), vol. 25, no. 4-5, pp. 279-293.

Gutwin, Carl, and Saul Greenberg (2002). A descriptive framework of workspace awareness for realtime groupware. Computer Supported Cooperative Work (CSCW), vol. 11, no. 3-4, pp. 411-446.

Hancock, Dawson R.; and Bob Algozzine (2016). Doing case study research: A practical guide for beginning researchers. New York: Teachers College Press.

Harari, Yuval N. (2016). Homo Deus: A brief history of tomorrow. New York: Random House.

Holman, Halsted; and Kate Lorig (2004). Patient self-management: a key to effectiveness and efficiency in care of chronic disease. Public health reports, vol. 119, no. 3, pp. 239-243.

Islind, Anna Sigridur (2018). Platformization: Co-designing Digital Platforms in Practice. Doctoral dissertation. University West, Sweden: School of Business, Economics and IT.

Islind, Anna Sigridur; and Ulrika Lundh Snis (2017). Learning in home care: a digital artifact as a designated boundary object-in-use. Journal of Workplace Learning, vol. 29, no. 7/8, pp. 577-587.

Islind, Anna Sigridur; and Ulrika Lundh Snis (2018). From Co-Design to Co-Care: Designing a Collaborative Practice in Care. Systems, Signs \& Actions, vol. 11, no. 1, pp. 1-24.

Islind, Anna Sigridur; Tomas Lindroth; Ulrika Lundh Snis; and Carsten Sørensen (2016). Co-creation and fine-tuning of boundary resources in small-scale platformization. In Scandinavian Conference on Information Systems, Basel: Springer, pp. 149-162. 
Islind, Anna Sigridur; Tomas Lindroth; Gunnar Steineck; and Johan Lundin (2019a). Shift in translations: Data work with patient-generated health data in clinical practice. Health informatics journal, 1460458219833097. https://doi.org/10.1177/1460458219833097.

Islind, Anna Sigridur; Tomas Lindroth; Gunnar Steineck; and Johan Lundin (2019b). Co-Designing a Digital Platform with Boundary Objects: Bringing Together Heterogeneous Users in Healthcare. Health \& Technology. Accepted for publication.

Johnston, Allen C.; James L. Worrell; Paul M. Di Gangi; and Molly Wasko (2013). Online health communities: An assessment of the influence of participation on patient empowerment outcomes. Information Technology \& People, vol. 26, no. 2, pp. 213-235.

Kahn, Jeremy M. (2015). Virtual visits - confronting the challenges of telemedicine. N Engl J Med, vol. 372 , no. 18 , pp. $1684-1685$.

Kalache, Alexandre; Isabella Aboderin; and Irene Hoskins (2002). Compression of morbidity and active ageing: key priorities for public health policy in the 21st century. Bulletin of the World Health Organization, vol. 80, no. 3, pp. 243-244.

Kaptelinin, Victor; and Bonnie Nardi (2012). Affordances in HCI: toward a mediated action perspective. SIGCHI 2012. In Proceedings of the SIGCHI conference on Human Factors in Computing Systems, Austin, US, 5-10 May 2012. New York: ACM, pp. 967-976.

Klein, Heinz K.; and Rudy Hirschheim (2008). The structure of the IS discipline reconsidered: Implications and reflections from a community of practice perspective. Information and Organization, vol. 18, no. 4, pp. 280-302.

Knorr-Cetina, Karin (2001). Objectual Practice, in Ted R. Schatzki, Karin Knorr-Cetina and E. von Savigny (eds): The Practice Turn in Contemporary Theory. London; New York: Routledge, pp. 184-197.

Koch, Sabine (2006). Home telehealth - current state and future trends. International journal of medical informatics, vol. 75 , no. 8, pp. 565-576.

Kress, Gunther (2009). Multimodality: A social semiotic approach to contemporary communication. London: Routledge.

Leonardi, Paul M. (2011). When flexible routines meet flexible technologies: Affordance, constraint, and the imbrication of human and material agencies. MIS Quarterly: Management Information Systems, vol. 35, no. 1, pp. 147-167.

Leonardi, Paul M. (2015). Studying work practices in organizations: Theoretical considerations and empirical guidelines. Annals of the International Communication Association, vol. 39, no. 1, pp. 235-273.

Leonardi, Paul M.; Bonnie A. Nardi; and Jannis Kallinikos (2012). Materiality and organizing: Social interaction in a technological world. Oxford: Oxford University Press.

LeRouge, Cynthia; Vasiliki Mantzana; and E. Vance Wilson (2007). Healthcare information systems research, revelations and visions. European Journal of Information Systems, vol. 16, no. 6, pp. 669-671.

Levina, Natalia; and Emmanuelle Vaast (2005). The emergence of boundary spanning competence in practice: Implications for implementation and use of information systems. MIS Quarterly, vol. 29, no. 2, pp. 335-363.

Maddams, Jacob; David H. Brewster; Anna Gavin; John Steward; Jim Elliott; Martin Utley; and Henrik Møller (2009). Cancer prevalence in the United Kingdom: estimates for 2008. British journal of cancer, vol. 101, no. 3, pp. 541-547.

Marwick, Alice E.; and Danah Boyd (2011). I tweet honestly, I tweet passionately: Twitter users, context collapse, and the imagined audience. New Media and Society, vol. 13, no. 1, pp. 114-133.

McGrenere, Joanna; and Wayne Ho (2000). Affordances: Clarifying and evolving a concept. In Graphics interface 2000. Proceedings of Graphics interface 2000, Canadian Human-Computer 
Communications Society, Toronto, Ontario, Canada, 28-30 May 2000. New York: ACM Press, pp. 179-186.

Milligan, Christine; Celia Roberts; and Maggie Mort (2011). Telecare and older people: who cares where?. Social science \& medicine, vol. 72, no. 3, pp. 347-354.

Nicolini, Davide (2012). Practice theory, work, and organization. Oxford: Oxford University Press.

Nicolini, Davide; Jeanne Mengis; and Jacky Swan (2012). Understanding the role of objects in crossdisciplinary collaboration. Organization science, vol. 23, no. 3, pp. 612-629.

Norman, Donald A. (1988). The psychology of everyday things. (The design of everyday things). New York: Basic Books.

Orlikowski, Wanda J. (2000). Using technology and constituting structures: A practice lens for studying technology in organizations. Organization science, vol. 11, no. 4, pp. 404-428.

Orlikowski, Wanda J. (2007). Sociomaterial practices: Exploring technology at work. Organization studies, vol. 28, no. 9, pp. 1435-1448.

Pawlowski, Suzanna D.; and Daniel Robey (2004). Bridging user organizations: Knowledge brokering and the work of information technology professionals. Mis Quarterly, vol. 28, no. 4, pp. 645-672.

Pickering, Andrew (2001) Practice and Posthumanism: Social Theory and a History of Agency. In Ted Schatzki; Karin Knorr-Cetina; and Eike Von Savigny (eds), The Practice Turn in Contemporary Theory. London: Routledge, pp. 163-174.

Pin, Stephanie; and Dario Spini (2016). Meeting the Needs of the Growing Very Old Population: Policy Implications for a Global Challenge. Journal of aging \& social policy, vol. 28, no. 3, pp. 218-231.

Pols, Jeannette (2010). The heart of the matter. About good nursing and telecare. Health Care Analysis, vol. 18, no. 4, pp. 374-388.

Pols, Jeannette; and Dick Willems (2011). Innovation and evaluation: taming and unleashing telecare technology. Sociology of health \& illness, vol. 33, no. 3, pp. 484-498.

Procter, Rob; Joe Wherton; Tish Greenhalgh; Paul Sugarhood; Mark Rouncefield; and Sue Hinder (2016). Telecare call centre work and ageing in place. Computer Supported Cooperative Work (CSCW), vol. 25, no. 1, pp. 79-105.

Roberts, Celia; Maggie Mort; and Christine Milligan (2012). Calling for Care: 'Disembodied' work, teleoperators and older people living at home. Sociology, vol. 46, no. 3, pp. 490-506.

Rochet, Jean-Charles; and Jean Tirole (2003). Platform Competition in Two-Sided Markets. Journal of the European Economic Association, vol. 1, no. 4, pp. 990-1029.

Rochet, Jean-Charles; and Jean Tirole (2006). Two-Sided Markets: A Progress Report. The RAND Journal of Economics, vol. 37, no. 3, pp. 645-667.

Scollon, Ron (2002). Mediated discourse: The nexus of practice. London: Routledge.

Shoebotham, Amie; and Neil S. Coulson (2016). Therapeutic affordances of online support group use in women with endometriosis. Journal of medical Internet research, vol. 18, no. 5 (2016): e. 109

Sørensen, Carsten; Mark De Reuver; and Rahul Basole (2015). Mobile Platforms and Ecosystems. Special issue editorial. Journal of Information technology, vol. 30, no. 5, pp. 195-197.

Stake, Robert E. (1995). The art of case study research. Thousand Oaks, CA: Sage.

Star, Susan Leigh; and James R. Griesemer (1989). Institutional Ecology, 'Translations' and Boundary Objects: Amateurs and Professionals in Berkeley's Museum of Vertebrate Zoology, 1907-39. Social Studies of Science, vol. 19, no. 3, pp. 387-420.

Stoffregen, Thomas A. (2003). Affordances as properties of the animal-environment system. Ecological psychology, vol. 15, no. 2, pp. 115-134.

Street, Richard L. Jr; Howard S. Gordon; Michael M. Ward; Edward Krupat; and Richard L. Kravitz (2005). Patient participation in medical consultations: why some patients are more involved than others. Medical care, vol. 43, no. 10, pp. 960-969. 
Tang, Charlotte; and Sheelagh Carpendale (2008). Evaluating the deployment of a mobile technology in a hospital ward. In CSCW'08. Proceedings of the 2008 ACM conference on Computer supported cooperative work, San Diego, USA, 8-12 November 2008. New York: ACM, pp. 205-214.

Tenenberg, Josh; Wolff-Michael Roth; and David Socha (2016). From I-awareness to we-awareness in CSCW. Computer Supported Cooperative Work (CSCW), vol. 25, no. 4-5, pp. 235-278.

Tiwana, Amrit; Benn Konsynsky; and Ashley A. Bush (2010). Platform Evolution: Coevolution of Platform Architecture, Governance, and Environmental Dynamics. Information Systems Research, vol. 21, no. 4, pp. 675-687.

Torenvliet, Gerard (2003). We can't afford it!: the devaluation of a usability term. Interactions, vol. 10, no. 4, pp. 12-17.

van Astyne, Marshall W.; Geoffrey G. Parker; and Sangeet P. Choudary (2016). Pipelines, platforms, and the new rules of strategy. Harvard Business Review, vol. 94, no. 4, pp. 16.

Van Osch, Wietske; and Orr Mendelson (2011). A typology of affordances: Untangling sociomaterial interactions through video analysis. ICIS 2011. The thirdy second International Conference on Information Systems Proceedings, Shanghai, China, 4-7 December 2011. AIS eLibrary. pp. 1-18.

Walsham, Geoff (1995). Interpretive case studies in IS research: nature and method. European Journal of information systems, vol. 4, no. 2, pp. 74-81.

Wareham, Jonathan; Paul B. Fox; and Josep L. Cano Giner (2014). Technology Ecosystem Governance. Organization science, vol. 25, no. 4, pp. 1195-1215.

Warrington, Lorraine; Kate Absolom; and Galina Velikova (2015). Integrated care pathways for cancer survivors-a role for patient-reported outcome measures and health informatics. Acta Oncologica, vol. 54, no. 5, pp. 600-608.

Wenger, Etienne (1999). Communities of practice: Learning, meaning, and identity. New York: Cambridge University Press.

Yin, Robert K. (2013). Validity and generalization in future case study evaluations. Evaluation, vol. 19, no. 3, pp. 321-332.

Yin, Robert K. (2017). Case study research and applications: Design and methods. Thousand Oaks, CA: Sage publications.

Zammuto, Raymond F.; Terri L. Griffith; Ann Majchrzak; Deborah J. Dougherty; and Samer Faraj (2007). Information technology and the changing fabric of organization. Organization science, vol. 18 , no. 5 , pp. $749-762$.

Publisher's Note Springer Nature remains neutral with regard to jurisdictional claims in published maps and institutional affiliations. 